\title{
Overview of Cannabis including Kampo Medicine and Therapy for Treatment of Dementia: A Review
}

\author{
Tibor Wenger ${ }^{1}$, Kazuhito Watanabe ${ }^{2}$, Yui Sasaki ${ }^{3}$, Keiko Kanazawa ${ }^{3}$, Koichi Shimizu ${ }^{3}$, \\ Supaart Sirikantaramas ${ }^{4}$, Yoshinari Shoyama ${ }^{5}$, Futoshi Taura ${ }^{6}$, Satoshi Morimoto ${ }^{7}$ and \\ Yukihiro Shoyama ${ }^{8 *}$
}

${ }^{1}$ Department of Anatomy, Histology and Embryology, Semmelweis University, Budapest, Hungary, ${ }^{2}$ Daiichi University of Pharmacy, Fukuoka, Japan, ${ }^{3}$ Association for Health Economics Research and Social Insurance and Welfare, Tokyo, Japan, ${ }^{4}$ Molecular Crop Research Unit, Department of Biochemistry, Faculty of Science, Chulalongkorn University, Bangkok, Thailand, ${ }^{5}$ Bonac Corporation, BIO Factory, Fukuoka, Japan, ${ }^{6}$ Faculty of Pharmacy and Pharmaceutical Science, Toyama, Japan, ${ }^{7}$ Faculty of Pharmaceutical Science, Fukuoka, Japan, ${ }^{8}$ Faculty of Pharmacy, Nagasaki International University, Nagasaki, Japan

Cannabis sativa L. is an annual herb oldest cultivated plants as a source of fiber since about 5000 B.C. On the other hand, the cannabis flower and seed are listed in Shennong's classic Materia Medica approximately 2000 years ago. The formulas prescribed with cannabis in Kampo medicine have been summarized. Cannabidiol (CBD) and tetrahydrocannabinol $(\mathrm{THC})$ are the major neurological and psychiatric cannabinoids, and develop to drugs. It becomes evident that the therapeutic CBD and/or THC are the important candidate of anti-dementia drugs having different mechanism for Alzheimer's patients. Two receptors and endocannabinoids are also discussed for underlying mechanism of action. In order to promote the breeding of cannabis plant containing higher concentration of target cannabinoid the biosynthetic enzymes were isolated, cloning and the tertiary structure of THCA synthase determined by x-ray analysis resulting in the possibility of molecular breeding for cannabinoids.

Keywords: Cannabis sativa, kampo medicine, cannabinoid biosynthetic enzyme, CB1 and CB2 receptor, antidementia

\section{INTRODUCTION}

Cannabis sativa L. (family Cannabaceae, formerly Moraceae) is an annual herb, commonly called marijuana or cannabis in addition to many regional names (Table 1). C. sativa L. is used by approximately $3 \%$ of the global population as a relaxant (United Nations Office on Drugs and Crime, 2017). Tetrahydrocannabinol (THC) and cannabidiol (CBD) are the major constituents of cannabis, known as cannabinoids, and both exhibit neurological and psychiatric activities (Cohen et al., 2019; Friedman et al., 2019).

Cannabis is among the oldest cultivated plants as has been used as a source of fiber since about 5000 B.C. At present, cannabis is cultivated worldwide, as the plant is adaptable to a wide range of temperatures. The cannabis seed is considered one of five grains together with bean, corn, millet, and Japanese barnyard millet, and was first recorded in China around 1000 B.C. Three herbs, including cannabis, safflower, and indigo, together with four trees, including the tea tree, mulberry plant, lacquer plant, and paper mulberry, have been cultivated in Japan for at least 1,000 years. Among these plants, cannabis is an important source of fiber, while safflower and indigo are used to obtain dyes for the production of clothing. The cannabis flower and seed are listed among 120 safe medicinals in 
TABLE 1 | Name of marihuana and its products in the world.

$\begin{array}{ll}\text { Country } & \text { Kame of marihuana } \\ \text { Algeria } & \begin{array}{c}\text { Nand its products } \\ \text { Brasil }\end{array} \\ \text { Edypt } & \text { Diamba, Djamba, Liamba, Riamba, Maconha, Meconha } \\ \text { Greek } & \text { Kamonga } \\ \text { India } & \text { Mavron } \\ \text { Jamaica } & \text { Ganja, Bhang, Charas } \\ \text { Lebanon } & \text { Ganga } \\ \text { Madagascar } & \text { Hashish el Keif } \\ \text { Mexico } & \text { Rongony } \\ \text { Morocco } & \text { Mariguana, Marihuana, Marijuana } \\ \text { Mozambique } & \text { Kif } \\ \text { Northwest Africa } & \text { Bangue, Suruma } \\ \text { South Africa } & \text { Chira, Chiras } \\ \text { Syria } & \text { Dagga } \\ \text { Tunisia } & \text { Hashish el Keif } \\ \text { Turkey } & \text { Takrouri } \\ \text { United States } & \text { Kobak } \\ \text { West indies } & \text { Mariguana, Marihuana, Marijuana } \\ & \text { Mariguana, Marihuana, Marijuana }\end{array}$

Shennong's classic Materia Medica, composed during the Eastern Han Dynasty (25-220 C.E.), which lists 365 species that are divided into three categories: safe (120 items), medicinal use (120 items), and toxic substances (125 items). Therefore, cannabis can be classified as a useful plant as a source of fiber and medicine.

Cannabis species contain 110 cannabinoids and 440 noncannabinoid compounds, including terpenoids, flavonoids, and sterols (Solymosi and Köfalvi, 2017). Therapeutic studies suggest that cannabis is clinically useful for the treatment of a wide range of pathological conditions, including neurological and psychiatric disorders (Cohen et al., 2019; Friedman et al., 2019). The major cannabinoids of cannabis include CBD, THC, cannabinol, and cannabichromene (Figure 1). Adams et al. (1940) were first to describe the structure of cannabinol, while Mechoulam and Shvo
(1963) and Gaoni and Mechoulam (1964) determined the structures of THC and CBD, including the positions of the double bonds and stereochemistries. Turner et al. (1980) noted the existence of 60 cannabinoids, which was increased to 70 in 2005. Elsohly et al. (2017) confirmed the isolation of 120 cannabinoids and elucidated the structures following the rapid development of analytical technologies, such as high-sensitivity mass spectrometry. It is believed that cannabinoids are sensitive against autooxidation, high temperature, lite and so on. In fact cannabinolic acid (CBNA) (Shoyama et al., 1970) and cannabicyclolic acid (CBLA) (Shoyama et al., 1972) are transformed from tetrahydrocannabinolic acid (THCA) and cannabichromenic acid (CBCA), respectively by photooxidation. However, recently Pacifici et al. (2017) confirmed that major cannabinoids, THCA and CBDA which are easily decarboxylated to give THC and $\mathrm{CBD}$, respectively by heating are still stable after 1 year storage as a plant form under dark condition. This phenomenon might be occurred from the evidence that THCA and CBDA are contained in the resin composed of mainly essential oil in glandular trichomes on leaves as a sealed form (Morimoto et al., 2007).

The cannabinoids THC and CBD are the only pharmacologically active constituents of cannabis (Figure 1) and are now widely used for the treatment of chemotherapyinduced nausea and vomiting, and weight loss and intractable seizure due to HIV/AIDS.

\section{KAMPO MEDICINE PRESCRIBED WITH CANNABIS}

The cannabis flower is classified as a safe substance in the Chinese medical text Shennong Ben Cao Jing for the treatment of trauma and to activate memory. In appropriate amounts, cannabis has psychological activities, but can cause mental illness excessive<smiles>[R]c1c(SCCCCCCCCCC)cc2c(c1O)C1C=C(C)CC[C@@H]1C(C)(C)O2</smiles>

THC: $\mathrm{R}=\mathrm{H}$ THCA: $\mathrm{R}=\mathrm{COOH}$<smiles>[R]c1c(SCCCCCCC)cc(O)c(C2C=C(C)CC[C@@H]2C(=C)C)c1O</smiles>

CBD: $\mathrm{R}=\mathrm{H}$ $\mathrm{CBDA}: \mathrm{R}=\mathrm{COOH}$<smiles>[R]c1c(CCCCCC)cc2c(c1O)C=C[C@@](C)(CCC=C(C)C)O2</smiles>

CBC: $\mathrm{R}=\mathrm{H}$ CBCA: $\mathrm{R}=\mathrm{COOH}$<smiles>[R]c1c(CCCCCCCCC)cc(O)c(C/C=C(\C)CCC=C(C)C)c1O</smiles><smiles>[R]c1c(CCCCCCCCCC)cc2c(c1O)-c1cc(C)ccc1C(C)(C)O2</smiles>

CBN: $\quad \mathrm{R}=\mathrm{H}$ CBNA: $\mathrm{R}=\mathrm{COOH}$

FIGURE 1 | Structures of major cannabinoids. 
amounts. Long-term intake of the seed and flower of cannabis has been proposed to maintain health. The Compendium of Materia Medica documented that the cannabis flower, called mafen, is applied as a psychotropic medication to stabilize the spirit and body to reach an immortal stage with a clear head when used in suitable amounts which might be related to anti-dementia activity as discussing in the next section. Leaves can be used for fiver and malaria. Recently Brand and Zhao (2017) introduced the mental effects of cannabis and long-term use linked to hallucinations and psychotic behaviors reported by Li Shizhen sixteen century. He Chinese surgeon Hua Tuo (140 208 C.E.) was recorded as the first physician to use cannabis with alcohol and herbs, known as mafeisan, as an anesthetic prior to surgery. The historical details of the use of mafeisan as an anesthetic drug remain a mystery (Rafe De Crespigny, 2007). However, recently Brand and Zhao (2017) confirmed that the anesthetic prescription for decreasing paint in China was the combination of cannabis and Datura species flower documented in the text Heart Text of Bian Que (1127-1270 AD).

The cannabis seed, known as mazi in Kampo medicine, is also classified as a safe substance that can enhance visceral functions and mood. When continuously consumed for prolonged periods, body fat is reduced allowing the user to have a more youthful appearance. Kampo medicines prescribed with cannabis seeds are widely used for treatment of constipation.

Mashiningan is composed of the Shojokito formulation, which includes immature orange, magnolia bark, peony root, and rhubarb to promote excretion. The addition of cannabis seed and apricot kernel, which are oily seeds, promotes smooth and mild excretion. Junchogan resembles the Mashiningan formulation with the addition of Japanese angelica root, rehmannia root, scutellaria root, and grilled licorice, which is used to promote fluid retention and mucus secretion in the large intestine, especially in the elderly. Meanwhile, the Junchogan formulation is used to treat habitual constipation in the elderly with no side effects.

Junsoto is similar to the Junchogan formulation with the addition of safflower to promote the circulation of body fluids (oketsu) and has almost same pharmacological activity as the Junchogan formulation. In these formulations, anthraquinone glycosides in rhubarb promote peristalsis in the large intestine, similar to sennosides, which can transfer a sugar moiety to anthraquinone via intestinal bacteria, resulting in the production of anthracene under anaerobic conditions. Anthracene derivatives stimulate excretion by the large intestine. In this formulation, cannabis seeds promote smooth over stimulation of the intestine because of the relatively high oil content.

On the other hand, Shakanzoto contains cannabis seed (to moisten the intestine), ginseng, broiled licorice and cinnamon, rehmannia root, ophiopogon tuber, and donkey-hide gelatin without rhubarb, which is used for shortness of breath and palpitations with constipation-like symptoms, lack of nutrients, dry skin, and fatigue. In this formulation, cannabis seeds function to moisten the intestine and induce detoxification. Long-term use is believed to promote youthfulness and lucidness as with the Shennong formulation.

\section{THERAPEUTIC MARIJUANA AND DEMENTIA}

The increase in human life expectancy has led to a surge in the prevalence of neurodegenerative disorders, especially dementia, worldwide. The incidence of dementia is projected to reach 81.1 million by the year 2040 (Ferri et al., 2005). In Japan, the number of dementia patients is expected to reach 7.3 million in the year 2025 and 10.2 million in 2050 (Figure 2) (National Institute of Public Health, 2015). Due to the rapid increase in the number of dementia patients, innovaventative strategies are urgently needed.

Fifth edition of the Diagnostic and Statistical Manual of Mental Disorders, the major types of dementia are Alzheimer's disease (AD), vascular dementia, frontal lobe hyperdermia, dementia with Lewy bodies, Parkinson's disease, Huntington's disease, and mixed dementia. Among these disorders, AD is the most common, followed by dementia with Lewy bodies and vascular dementia. AD, which accounts for an estimated $30 \%$ of dementia cases, affects 33 million people worldwide. Typical causes of $\mathrm{AD}$ include neuroinflammation and oxidative stress in the brain resulting in the accumulation of amyloid- $\beta(A \beta)$ plaques and tau hyperphosphorylation. It is clear that the risk of $\mathrm{AD}$ increases with age, but lifestyle and dietary habits are closely related to the development of dementia.

Many studies have identified various compounds with antidementia activities, as determined by analysis of acetylcholinesterase inhibitors (Ho et al., 2011; Natarajan et al., 2013). However, galantamine (from Galanthus caucasicus and G. woronowii) is the only natural acetylcholinesterase inhibitor currently available for clinical use. Recently, donepezil and rivistagmine have been approved for clinical use as synthetic acetylcholinesterase inhibitors, and memantine as a N-methyl-D-aspartate receptor antagonist for $\mathrm{AD}$ patients (Mangialasche et al., 2010). However, the side effects of acetylcholinesterase inhibitors include nausea, diarrhea, and weight loss (Kaduszkiewicz et al., 2005), while those of memantine include hallucinations, dizziness, and fatigue (Parsons et al., 1999).

THC has been approved for medicinal use by the Food and Drug Administration as a safe and effective treatment for nausea and vomiting induced by chemotherapy, and weight loss due to HIV/AIDS. THC is marketed under the names Dronabinol, Adversa, Syndros, Marinol, and Reduvo for the treatment of nausea, vomiting, weight loss, and sleep apnea. CBD under the name Epidiolex was approved in the United States and European Union in 2018 and 2019, respectively, for the treatment of intractable seizures, especially intractable epilepsy.

THC inhibits acetylcholinesterase activity and prevents aggregation of $\mathrm{A} \beta$-plaques in vitro (Eubanks et al., 2006). On the other hand, CBD might have antioxidant activities that could affect the metabolism of anandamide, although the underlying mechanism and receptor remain unclear (Campillo and Paez, 2009; Iuvone et al., 2009; Iuvone et al., 2009). A $\beta$-induced neurotoxicity was protected by $\mathrm{CBD}$ in vitro. Furthermore, following challenge with $\mathrm{A} \beta$ proteins in vitro, $\mathrm{CBD}$ inhibited intracellular signaling pathways and suppressed tau protein 


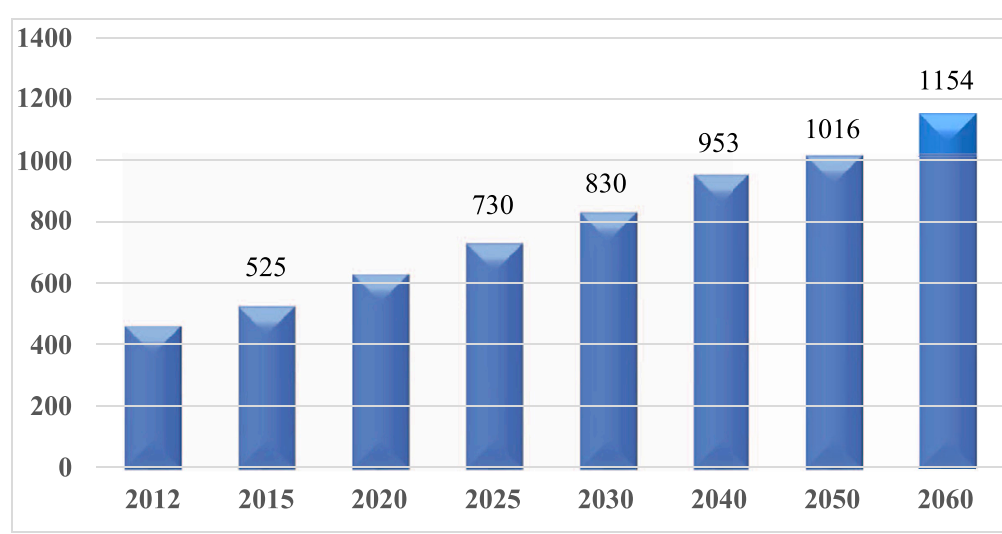

FIGURE 2 | Increases of dementia patients in Japan.

hyperphosphorylation (Esposito et al., 2006a) and nitric oxide production (Esposito et al., 2006b). When the mouse hippocampus was injected with $\mathrm{A} \beta$ proteins, $\mathrm{CBD}$ induced dose-dependent suppression of the proinflammatory factors interleukin-1 $\beta$ and nitric oxide (Esposito et al., 2007).

Therefore, CBD may act against oxidative stress and tau phosphorylation in $\mathrm{AD}$ without the risk of the psychological side effects of THC.

A recent study assessed CBD for the prevention and treatment of $\mathrm{AD}$ (Georgia et al., 2017). An in vivo study conducted by Watt and Karl (2017) reported that CBD has therapeutic potential for treatment of $\mathrm{AD}$. CBD exhibited anti-oxidative, neuroprotective, anti-inflammatory activities in mice injected with human $A \beta$ proteins, while transgenic APPxPS1 mice developed A $\beta$ plaques in the hippocampus and cortex. $\mathrm{CBD}$ decreased $\mathrm{A} \beta$ plaqueinduced reactive gliosis and decreased iNOS and interleukin$1 \beta$ protein levels, resulting reduced inflammation of neuronal tissues and subsequent neurogenesis, while preventing cognitive deficits in an animal model of AD.

Moreover, administration of a combination of CBD and THC resulted in greater therapeutic activity than with $\mathrm{CBD}$ alone, likely due to the antagonistic response of CBD. Based on these findings, $\mathrm{CBD}$ is strong candidate as a prophylactic for $\mathrm{AD}$ because the pharmacological mechanism and efficacy are completely different than those of current drugs. Furthermore, $\mathrm{CBD}$ can be used clinically without the psychological side effects of THC and no concern about potential abuse.

Recently several systematic reviews have been reported. Kim et al. (2019) reviewed the publications related to the use of cannabinoid for dementia and evaluated that CBD was useful for the treatment and prevention for $\mathrm{AD}$. For example $\mathrm{CBD}$ protects $\mathrm{PC}-12$ cells against $\mathrm{A} \beta$ neurotoxicity and oxidation stress. Moreover, CBD inhibit acetylcholinesterase to promote memory, stimulate the neurogenesis of the hippocampus, strengthen cell survival by reducing ROS production and lipid peroxidation and so on. They concluded that the combination of $\mathrm{CBD}$ and THC was more effective in memory than CBD or THC alone although the psychotropic activity of THC appeared, Twelve studies were associated with inclusion criteria. Study designs were relatively scattered such as randomized controlled trials (50\%) and the drug of cannabinoids, dronabinol (33\%), nabilone (25\%) or THC (42\%). Among them dronabinol and THC were associated with significant improvements in a range of neuropsychiatric scores. The most common side effect reported was sedation. Studies under low doses of cannabinoids were evaluated to be not enough efficacy.

Although it was not proven in a randomized control trial, the observational studies showed promising results for patients having refractory symptoms. The safety evidence is good and mild. Authors suggested that dose increase and formulations having appropriated bioavailability will be needed in future (Hillen et al., 2019).

Ten female demented patients with severe behavior problems received an oral intact of higher dosages of THC and CBD likely increasing to $9.0 \mathrm{mg} \mathrm{THC} / 18.0 \mathrm{mg} \mathrm{CBD}$ after 2 months compared to the other studies, and were well tolerated and improved behavior problems, rigidity, and daily care in severely demented patients (Broers et al., 2019).

A systematic review of randomized controlled trials reported that THC is effective against the cognitive symptoms of dementia, although evidence was less than convincing (Charernboon et al., 2021).

\section{POTENTIAL BENEFITS}

Cannabis, which can be classified as a fiber, grain, oil, and/or medicine, is used by only $3 \%$ of the global population. The cannabis flower and seed have been successfully used for the treatment of psychological disorders. As mentioned above, ligands for the two types of THC receptors, CB1 (Matsuda et al., 1990) and CB2 (Munro et al., 1993) identified in the brain and macrophage, respectively, were identified as anandamide (Devane et al., 1992) and 2-arachidony glyceride (Sugiura et al., 1995). These findings have promoted the medical use of cannabinoids directly and further research of drug development from the cannabinoids THC and CBD. 
Long-term use of marijuana can result in "cannabis psychosis," which is characterized by the development of psychotomimetic and psychiatric disorders and mental instability. Also, decreased short-term potentiation and a motivational syndrome have been reported in younger people who repeatedly use marijuana (George, 2017).

However, since decriminalization policy against marihuana have been spread worldwide, the potentiality of marihuana for therapeutic use are growing louder (World drug report, 2021). In fact Brunetti et al. suggested the appropriate dosages, the analytical way of cannabinoids and the concentration of cannabinoids in marihuana prepared from different sources of herbal cannabis for prescribing doctors (Brunetti et al., 2020).

\section{CANNABINOID RECEPTORS AND ENDOCANNABINOID}

Two receptors and endocannabinoids will be discussed for underlying mechanism of action of cannabinoids. The ligands of two types of THC receptors, CB1 (Matsuda et al., 1990) and CB2 (Munro et al., 1993) in the brain and macrophage, respectively, were identified as arachidonoylethanolamide (anandamide) (Devane et al., 1992) and two- arachidony glyceride (Sugiura et al., 1995). It became evident that 2arachidony glyceride is a potent ligand with high affinity for both the $\mathrm{CB} 1$ and $\mathrm{CB} 2$ receptors and the content is higher in rat brain than that of anandamide (Murielle et al., 1994). In 1998 Murielle et al. (1998) identified a selective antagonist for the CB2 receptor.

CB1 Receptor: Matsuda et al. (1990) was first to isolate, clone, and sequence a central cannabinoid receptor. Gerard et al. (1990) reported that cannabinoid receptors of the human and rat shared a $98 \%$ amino acid homology. The human cannabinoid receptor, which belongs to the seven trans-membrane spanning receptor family, assumes a three-dimensional conformation with 1) seven helices spanning from one side of the cell, 2) three extra-cellular and three intracellular loops, 3) a glycosylate extra-cellular $\mathrm{N}$-terminal domain, and 4) an intracellular C-terminal domain involved in interactions with a $\mathrm{G}$ protein, which is responsible for the trans-membrane transduction of the receptor-mediated signal. Hua et al. (2016) elucidated the crystal structure of human CB1 and, Moldrich and Wenger (2000) used an immunohistochemical technique to identify a CB1 receptor in the rat brain and to elucidate the distribution in several other organs.

CB2 Receptor: A peripheral cannabinoid receptor, named $\mathrm{CB} 2$, was identified in the human spleen and was also identified as a $\mathrm{G}$ protein coupled 7-trans-membrane spanning receptor with $44 \%$ sequence identity with the $\mathrm{CB} 1$ receptor (Munro et al., 1993).

Recent advancements in endocannabinoid research have shown that most of pharmacological properties of anandamide are similar in the central nervous system (CNS) and peripheral systems with THC and other active cannabinoids, especially in regard to 1) the inhibitory effects on memory, motor activity and turning behavior (Lichtman et al., 1995; Romero et al., 1995;

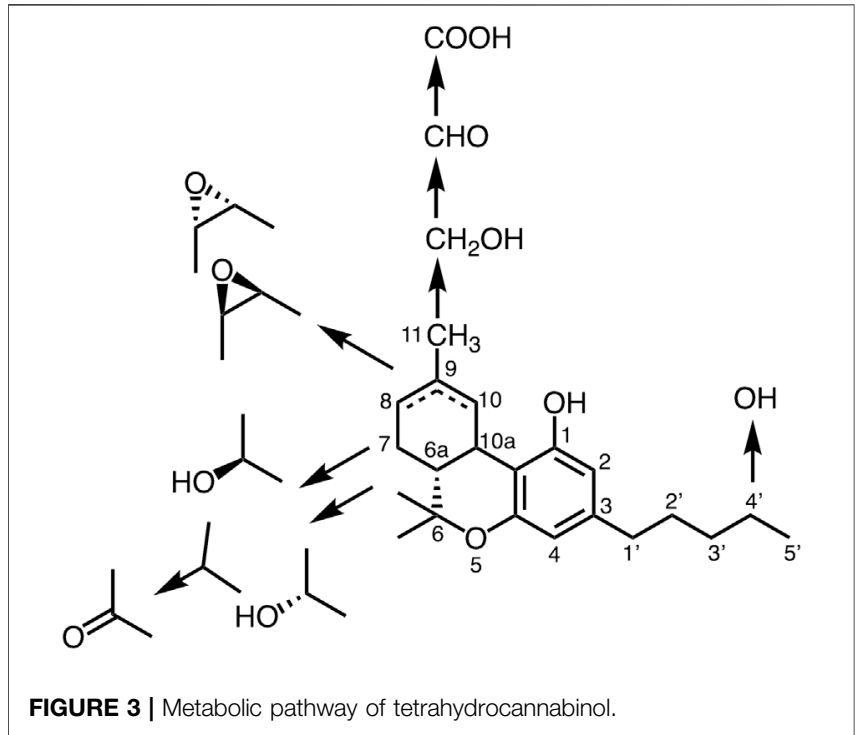

Terranova et al., 1995), 2) ocular blood pressure and heart rate (Varga et al., 1995; Weidenfeld et al., 1994, 3) regulation of hormones involved in the hypothalamus-pituitary-adrenal axis (Giannikou et al., 1995; Wenger et al., 1995), 4) neurotransmission mediated by dopamine, acetylcholine, noradrenalin, endorphin, glutamate, and gamma-aminobutyric acid (Wickens and Pertwee, 1993; Ishac et al., 1996, and 5) the immune response (Schuel et al., 1994; Schwarz et al., 1994). Since some of these functions are closely related to the CNS, therapeutic cannabinoids were discussed previously.

\section{CANNABINOID METABOLIC PATHWAYS}

THC is transformed to the oxidative metabolites quickly as indicated in Figure $\mathbf{3}$ and their activities are changeable (Watanabe et al., 2000). To detect various kind of metabolites against THC a monoclonal antibody (mAb) against THCA was prepared in our lab (Goto et al., 1994; Tanaka and Shoyama, 1999). Interestingly, the anti-THCA mAb was cross-reactive against all metabolites of THC (Figure 3), CBD, and cannabinol. Furthermore, in vitro and in vivo analyses revealed rapid oxidation of THC occurred at several sites and the molecule was metabolized into hydroxyl, epoxide, aldehyde and carboxylic acid derivatives in the body. Fortunately, the mAb recognized only limited cannabinoids, but not lipophilic compounds, such as cholesterol, testosterone, $\beta$-carotene, and androstene- 3,17-dione, or the endogenous cannabinoid anandamide (Watanabe et al., 2000). An eastern blotting system will allow for one-step analysis of cannabinoid metabolites, which would be useful for pharmacological and biological analyses of cannabinoids (Shan et al., 2001). Metabolites of THC in the body are important for the bioavailability and affinity of enzymes and/or receptors. The THC metabolic pathway is shown in Figure 3 (Watanabe et al., 2005).

Elmes et al. (2015) reported a new finding related to cannabinoid metabolism that THC and CBD are carried by 


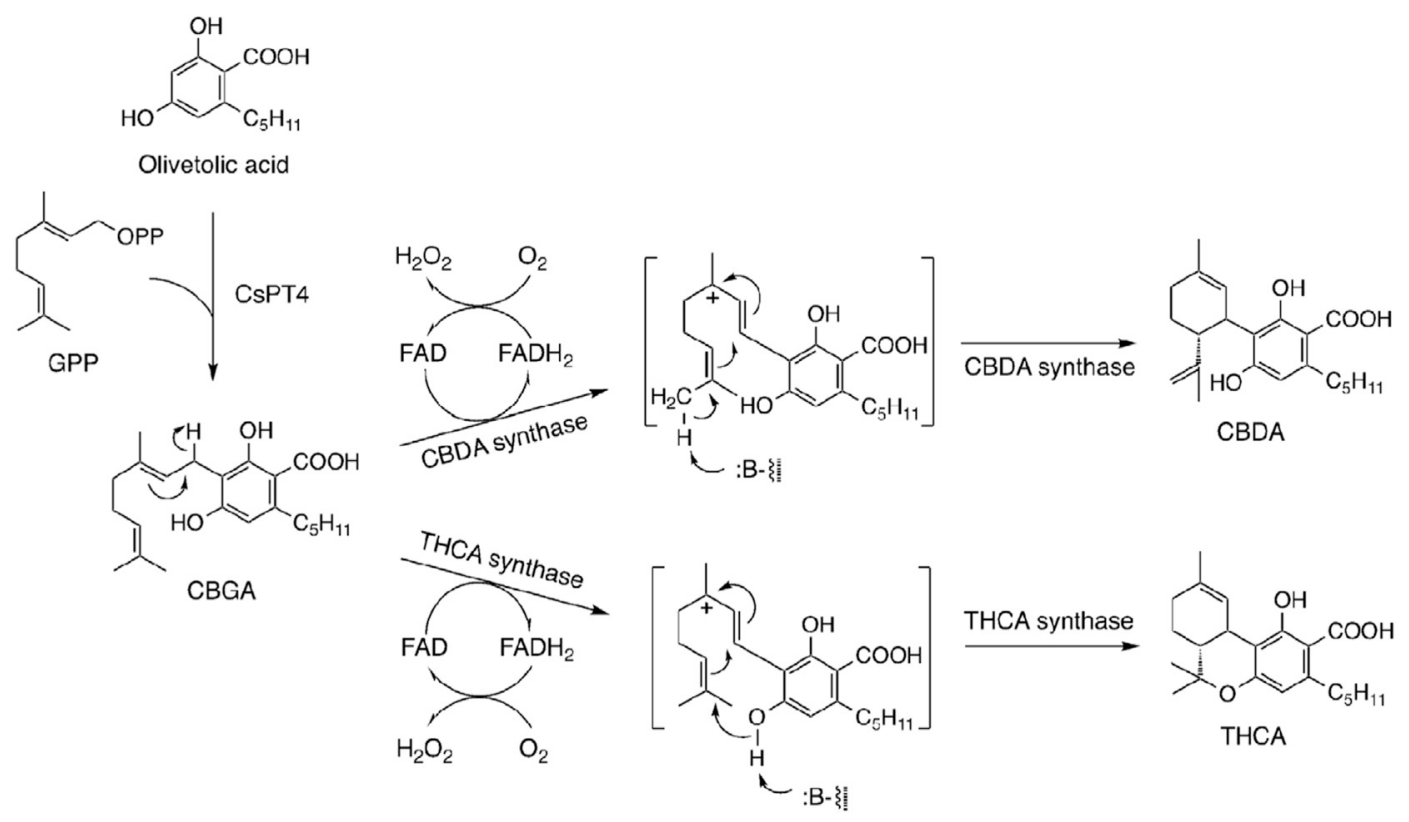

FIGURE 4 | Biosynthetic pathway of CBDA and THCA [Furthermore, recently cannabinoid prenyltransferase 4 was found in C. sativa (Luo et al., 2019)].

fatty acid-binding proteins (FABP1). Further, it becomes evident that FABP1 carries and preserves THC in ligand binding pocket temporarily, then transports to intracellular CYP450 enzymes for THC metabolism (Elmes et al., 2019) as described previously.

\section{CANNABINOID BIOSYNTHESIS PATHWAY}

Recently Luo et al. (2019) succeeded to fix the biosynthetic matrix for preparation of CBGA, CBDA, THCA, tetrahydrocannabivarinic acid (CBDVA) and cannabidivarinic acid (CBDVA) (Shoyama et al., 1977) in yeast. However, since the molecular breeding for cannabinoids is needed in future, the biosynthetic enzymes of cannabinoids including isolation, cloning and the tertiary structure of THCA synthase will be discussed for further investigation based on the newly developed methodology called as missile type molecular breeding (Putalun et al., 2003; Sakamoto et al., 2012; Putalun et al., 2015).

Studies on the biosynthesis of cannabinoids started in the 1960s with the use of isotope tracers. Cannabinoids are biosynthesized via the conjugation of acetyl-malonate and mevalonate (Shoyama et al., 1994). Stout et al. (2012) confirmed that the hexanoyl-CoA formed by the acylactivating enzyme was a precursor of cannabinoids. The conjugation of olivetorate and monoterpene moiety was occurred by a transferase to yield CBGA, the key precursor of CBDA and THCA (Fellermeier and Zenk, 1988). Further it become evident that olivetol synthase, a polyketide synthase was an essential enzyme for the biosynthesis of cannabinoids (Taura et al., 2009).

Since the biosynthetic pathway was confirmed in the 1990s, three enzymes related to cannabinoid biosynthesis were isolated

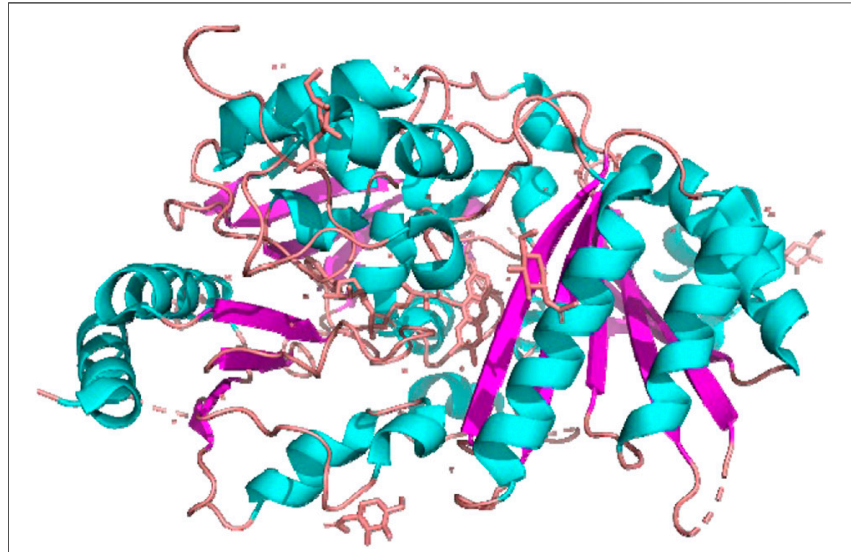

FIGURE 5 | Structure of THCA synthase by X-ray crystallography.

and purified from cannabis plants: THCA synthase (Taura et al., 1995), CBDA synthase (Taura et al., 1996), and cannabichromenic acid (CBCA) synthase (Morimoto et al., 1998). cDNA cloning of THCA synthase produces a transgenic protein (Sirikantaramas et al., 2004; Taura et al., 2007a), which is an important finding. THCA synthase is a flavoenzyme with high homology with the berberine bridge enzyme (Dittrich and Kutchan, 1991), which catalyzes oxidative cyclization of reticuline to scoulerine in the biosynthesis of benzylisoquinoline alkaloids (Zenk, 1985). These findings were confirmed by overexpression of recombinant enzymes using a baculovirus-insect cell system (Sirikantaramas et al., 2004; Sirikantaramas et al., 2005; Taura et al., 2009). CBDA synthase was also cloned and expressed as a 
recombinant enzyme (Taura et al., 2007b; Taura et al., 2007c). The cannabinoid biosynthetic pathway involves direct biosynthesis of THCA and CBDA from CBGA by CBDA synthase and THCA synthase, respectively (Figure 4).

Information on biosynthesis of cannabinoids has resulted in the crystallization and structure of THCA synthase. The enzyme was overproduced in baculovirus, and crystalized (Shoyama et al., 2005; Taguchi et al., 2008). Then, the tertiary structure was determined by X-ray crystallography at $0.75 \AA$ resolution (Figure 5) (Shoyama et al., 2012).

The most typical characteristic of the THCA synthase molecule is a residue that binds flavin adenine dinucleotide (FAD). Based on this analysis, CBGA was identified as a substrate and THCA as a product that competed to fit into the pocket of the active site (Figure 3). Mutation experiments at the active site resulted decreased enzymatic activity of THCA synthase, but not complete inhibition. These findings suggest that the active site may function by binding with CBGA as a substrate. Therefore, the tertiary structure explains the enzymatic reaction of THCA formation from CBGA (Figure 2).

Luo et al. (2019) succeeded to set up the biosynthetic system using yeast for CBGA, CBDA, THCA, tetrahydrocannabivarinic acid (CBDVA) (Shoyama et al., 1977) and cannabidivarinic acid (CBDVA) (Shoyama et al., 1977) production without the organic synthesis and/or Cannabis plant. This methodology may open a new platform for preparation of natural products. Further the authors reviewed biochemistry and biotechnology on cannabinoids including new advance (Taura et al., 2019).

Cannabis can be divided into CBDA- and THCA-type strains (Kushima et al., 1980). Authors group previously successfully bred a CBDA strain by the repeated crossing that mainly produced CBDA as a precursor of CBD, which was simply transformed by hort-term heating, during 5 min (Shoyama, 1993). Moreover, a mutation to THCA synthase could completely inhibit THCA synthesis and increase the CBDA content (Sirikantaramas et al., 2004). The "missile-type molecular breeding" method is a unique breeding technology in which a single chain fragment variable $(\mathrm{scFv})$ gene is transformed into the host plant (CBDA strain) resulting in a three-fold increase in antigen molecules (Putalun et al., 2003; Sakamoto et al., 2012; Putalun et al., 2015). In this case, the $\mathrm{scFv}$ gene targeted by an anti-CBDA mAb was induced into the CBDA strain, resulting in an increased the concentration of CBDA by up to three-fold as compared to that of the original plant. These technologies strongly support the development of $\mathrm{CBD}$ as a drug to prevent $\mathrm{AD}$ as documented previously.

\section{CONCLUSION}

C. sativa are listed as safe substances in the Chinese medical text Shennong Ben Cao Jing to maintain health and brain function at suitable dosages. The Kampo medicine such as Daiokanzoto prescribed with rhubarb and licorice can be used for the treatment of constipation in healthy persons as this formulation can cause diarrhea in the frail and elderly. Mashiningan formulation promotes milder defecation, although the high concentration of oil might be affected by the CNS to maintain mental stability without any adverse side effects.

CBD is an effective drug for the treatment of intractable seizures, especially intractable pilepsy. A recent neuronal investigation (Georgia et al., 2017) found that CBD blocked $\mathrm{A} \beta$-induced neurotoxicity, tau protein hyperphosphorylation, and the activities of iNOS and interleukin- $1 \beta$, highlighting a unique pharmacological mechanism as compared to currently approved anti-dementia drugs, resulting in reduced inflammation in neuronal tissues and neurogenesis for the treatment of dementia.

Two receptors, CB1 and CB2, and endocannabinoids, anandamide and 2-arachidony glyceride are discussed for underlying mechnism of action of cannabinoids in the brain. It became evident that 2-arachidony glyceride is a potent ligand with high affinity for both the $\mathrm{CB} 1$ and $\mathrm{CB} 2$ receptors. Endocannabinoid research have shown that most of pharmacological activities of anandamide are similar with THC and CBD in the CNS and peripheral systems. Metabolic pathway of THC is discussed because the metabolic speed is faster and the activity of THC decrease rapidly.

In order to make evident the biosynthetic enzyme system which has possibility for the production of higher concentration of cannabinoids, their enzymes were isolated and cloned. THCA synthase is a flavoenzyme that efficiently catalyzes oxidative cyclization of CBGA. The tertiary structure THCA synthase was determined by X-ray crystallography (Shoyama et al., 2012). This finding suggests the potential of molecular breeding of cannabis plants. For example, the cleavage of FAD from THCA synthase in the CBDA strain enhances biosynthesis of CBDA. This technology can increase the CBDA content in cannabis plants and further the development of new CBD-based drugs without the risks of psychological disorders and abuse for the prevention of dementia, especially $\mathrm{AD}$.

\section{AUTHOR CONTRIBUTIONS}

WT prepared the section on endo-cannabinoid and its receptor. KW wrote the section on cannabinoid metabolism. YSa, KK, and KS collected and discussed the comprehensive data on marijuana. SS worked on the cloning of THCA synthase and the expression system. YoS investigated the crystallization and X-ray analysis of THCA synthase. FT worked on the cloning and gene construction. SM purified the biosynthetic enzymes related to cannabinoids. YkS prepared the manuscript and managed the study.

\section{ACKNOWLEDGMENTS}

The authors sincerely thank the Faculty of Pharmacy of Nagasaki International University for providing the facilities to support this project and the Association for Health Economics Research and Social Insurance and Welfare for financial support. 


\section{REFERENCES}

Adams, R., Baker, B. R., and Wearn, R. B. (1940). Structure of Cannabinol. III. Synthesis of Cannabinol, 1-Hydroxy-3-N-Amyl-6,6,9-Trimethyl-6Dibenzopyran1. J. Am. Chem. Soc. 62, 2204-2207. doi:10.1021/ja01865a083

Brand, E. J., and Zhao, Z. (2017). Cannabis in Chinese Medicine: Are Some Traditional Indications Referenced in Ancient Literature Related to Cannabinoids? Front. Pharmacol. 8, 108. doi:10.3389/fphar.2017.00108

Broers, B., Patà, Z., Mina, A., Wampfler, J., de Saussure, C., and Pautex, S. (2019). Prescription of a THC/CBD-Based Medication to Patients with Dementia: A Pilot Study in Geneva. Med. Cannabis Cannabinoids. 2 (1), 56-59. doi:10.1159/ 000498924

Brunetti, P., Pichini, S., Pacifici, R., Busardò, F. P., and Del Rio, A. (2020). Herbal Preparations of Medical Cannabis: A Vademecum for Prescribing Doctors. Medicina (Kaunas). 56, 237. doi:10.3390/medicina56050237

Campillo, N. E., and Páez, J. A. (2009). Cannabinoid System in Neurodegeneration: New Perspectives in Alzheimer's Disease. Mini Rev. Med. Chem. 9, 539-559. doi:10.2174/138955709788167628

Charernboon, T., Lerthattasilp, T., and Supasitthumrong, T. (2021). Effectiveness of Cannabinoids for Treatment of Dementia: A Systematic Review of Randomized Controlled Trials. Clin. Gerontol. 44, 16-24. doi:10.1080/ 07317115.2020 .1742832

Cohen, K., Weizman, A., and Weinstein, A. (2019). Positive and Negative Effects of Cannabis and Cannabinoids on Health. Clin. Pharmacol. Ther. 105, 1139-1147. doi:10.1002/cpt.1381

Devane, W. A., Hanus, L., Breuer, A., Pertwee, R. G., Stevenson, L. A., Griffin, G., et al. (1992). Isolation and Structure of a Brain Constituent that Binds to the Cannabinoid Receptor. Science. 258, 1946-1949. doi:10.1126/science.1470919

Dittrich, H., and Kutchan, T. M. (1991). Molecular Cloning, Expression, and Induction of Berberine Bridge Enzyme, an Enzyme Essential to the Formation of Benzophenanthridine Alkaloids in the Response of Plants to Pathogenic Attack. Proc. Natl. Acad. Sci. U S A. 88, 9969-9973. doi:10.1073/pnas.88.22.9969

Elmes, M. W., Kaczocha, M., Berger, W. T., Leung, K., Ralph, B. P., Wang, L., et al. (2015). Fatty Acid-Binding Proteins (FABPs) Are Intracellular Carriers for $\Delta 9$ tetrahydrocannabinol (THC) and Cannabidiol (CBD). J. Biol. Chem. 290 (14), 8711-8721. doi:10.1074/jbc.M114.618447

Elmes, M. W., Prentis, L. E., McGoldrick, L. L., Giuliano, C. J., Sweeney, J. M., Joseph, O. M., et al. (2019). FABP1 Controls Hepatic Transport and Biotransformation of $\Delta 9$-THC. Sci. Rep. 9, 7588. doi:10.1038/s41598-01944108-3

ElSohly, M. A., Radwan, M. M., Gul, W., Chandra, S., and Galal, A. (2017). "Phytochemistry of Cannabis Sativa L," in Phytocannabinoids, Progress in the Chemistry of Organic Natural Products. Editors A. D. H. KinghornFalk, S. Gibbons, and J. Kobayashi, 103, 1-36. doi:10.1007/978-3-319-45541-9_1

Esposito, G., De Filippis, D., Carnuccio, R., Izzo, A. A., and Iuvone, T. (2006a). The Marijuana Component Cannabidiol Inhibits Beta-Amyloid-Induced Tau Protein Hyperphosphorylation through Wnt/beta-Catenin Pathway Rescue in PC12 Cells. J. Mol. Med. (Berl). 84, 253-258. doi:10.1007/s00109-0050025-1

Esposito, G., De Filippis, D., Maiuri, M. C., De Stefano, D., Carnuccio, R., and Iuvone, T. (2006b). Cannabidiol Inhibits Inducible Nitric Oxide Synthase Protein Expression and Nitric Oxide Production in Beta-Amyloid Stimulated PC12 Neurons through P38 MAP Kinase and NF-kappaB Involvement. Neurosci. Lett. 399, 91-95. doi:10.1016/j.neulet.2006.01.047

Esposito, G., Scuderi, C., Savani, C., Steardo, L., Jr., De Filippis, D., Cottone, P., et al. (2007). Cannabidiol In Vivo Blunts Beta-Amyloid Induced Neuroinflammation by Suppressing IL-1beta and iNOS Expression. Br. J. Pharmacol. 151, 1272-1279. doi:10.1038/sj.bjp.0707337

Eubanks, L. M., Rogers, C. J., Beuscher, A. E., Koob, G. F., Olson, A. J., Dickerson, T. J., et al. (2006). A Molecular Link Between the Active Component of Marijuana and Alzheimer's Disease Pathology. Mol. Pharm. 3, 773-777. doi:10.1021/mp060066m

Fellermeier, M., and Zenk, M. H. (1988). Prenylation of Olivetolate by a Hemp Transferase Yields Cannabigerolic Acid, the Precursor of Tetrahydrocannabinol. FEBS Lett. 427 (2), 283-285. doi:10.1016/s00145793(98)00450-5
Ferri, C. P., Prince, M., Brayne, C., Brodaty, H., Fratiglioni, L., Ganguli, M., et al. (2005). Global Prevalence of Dementia: a Delphi Consensus Study. Lancet. 366, 2112-2117. doi:10.1016/S0140-6736(05)67889-0

Friedman, D., French, J. A., and Maccarrone, M. (2019). Safety, Efficacy, and Mechanisms of Action of Cannabinoids in Neurological Disorders. Lancet Neurol. 18, 504-512. doi:10.1016/S1474-4422(19)30032-8

Gaoni, Y., and Mechoulam, R. (1964). Isolation, Structure, and Partial Synthesis of an Active Constituent of Hashish. J. Am. Chem. Soc. 86, 1646-1647. doi:10. 1021/ja01062a046

Georgia, W., and Karl, T. (2017). In vivo Evidence for Therapeutic Properties of Cannabidiol (CBD) for Alzheimer's Disease. Front. Pharmacol. 8, 20. doi:10. 3389/fphar.2017.00020

Gérard, C., Mollereau, C., Vassart, G., and Parmentier, M. (1990). Nucleotide Sequence of a Human Cannabinoid Receptor cDNA. Nucleic Acids Res. 18, 7142. doi:10.1093/nar/18.23.7142

Giannikou, P., Yiannakakis, N., Frangkakis, G., Probonas, K., and Wenger, T. (1995). Anandamide (Endogen Cannabinoid) Decreases Serum Prolactin in Pregnant Rat. Neuro Endocrinol. Lett. 17, 281-287.

Goto, Y., Shima, Y., Morimoto, S., Shoyama, Y., Murakami, H., Kusai, A., et al. (1994). Determination of Tetrahydrocannabinolic Acid-Carrier Protein Conjugate by Matrix-Assisted Laser Desorption/ionization Mass Spectrometry and Antibody Formation. Org. Mass. Spectrom. 29, 668-671. doi:10.1002/oms.1210291115

Hillen, J. B., Soulsby, N., Alderman, C., and Caughey, G. E. (2019). Safety and Effectiveness of Cannabinoids for the Treatment of Neuropsychiatric Symptoms in Dementia: a Systematic Review. Ther. Adv. Drug Saf. 10, 2042098619846993. doi:10.1177/2042098619846993

Ho, Y. S., So, K. F., and Chang, R. C. (2011). Drug Discovery from Chinese Medicine against Neurodegeneration in Alzheimer's and Vascular Dementia. Chin. Med. 6, 15. doi:10.1186/1749-8546-6-15

Hua, T., Vemuri, K., Pu, M., Qu, L., Han, G. W., Wu, Y., et al. (2016). Crystal Structure of the Human Cannabinoid Receptor CB1. Cell. 167, 750-e14. doi:10. 1016/j.cell.2016.10.004

Ishac, E. J., Jiang, L., Lake, K. D., Varga, K., Abood, M. E., and Kunos, G. (1996). Inhibition of Exocytotic Noradrenaline Release by Presynaptic Cannabinoid CB1 Receptors on Peripheral Sympathetic Nerves. Br. J. Pharmacol. 118, 2023-2028. doi:10.1111/j.1476-5381.1996.tb15639.x

Iuvone, T., Esposito, G., De Filippis, D., Scuderi, C., and Steardo, L. (2009). Cannabidiol: a Promising Drug for Neurodegenerative Disorders? CNS Neurosci. Ther. 15, 65-75. doi:10.1111/j.1755-5949.2008.00065.x

Kaduszkiewicz, H., Zimmermann, T., Beck-Bornholdt, H. P., and van den Bussche, H. (2005). Cholinesterase Inhibitors for Patients with Alzheimer's Disease: Systematic Review of Randomised Clinical Trials. BMJ. 331, 321-327. doi:10. 1136/bmj.331.7512.321

Kim, S. H., Yang, J. W., Kim, K. H., Kim, J. U., and Yook, T. H. (2019). A Review on Studies of Marijuana for Alzheimer's Disease-Focusing on CBD, THC. J. Pharmacopuncture. 22, 225-230. doi:10.3831/KPI.2019.22.030

Kushima, H., Shoyama, Y., and Nishioka, I. (1980). Cannabis. XII. Variations of Cannabinoid Contents in Several Strains of Cannabis Sativa L. With Leaf-Age, Season and Sex. Chem. Pharm. Bull. 28, 594-598. doi:10.1248/cpb.28.594

Lichtman, A. H., Dimen, K. R., and Martin, B. R. (1995). Systemic or Intrahippocampal Cannabinoid Administration Impairs Spatial Memory in Rats. Psychopharmacology (Berl). 119, 282-290. doi:10.1007/ BF02246292

Luo, X., Reiter, M. A., d’Espaux, L., Wong, J., Denby, C. M., Lechner, A., et al. (2019). Complete Biosynthesis of Cannabinoids and Their Unnatural Analogues in Yeast. Nature. 567, 123-126. doi:10.1038/s41586-019-0978-9

Mangialasche, F., Solomon, A., Winblad, B., Mecocci, P., and Kivipelto, M. (2010). Alzheimer's Disease: Clinical Trials and Drug Development. Lancet Neurol. 9, 702-716. doi:10.1016/S1474-4422(10)70119-8

Matsuda, L. A., Lolait, S. J., Brownstein, M. J., Young, A. C., and Bonner, T. I. (1990). Structure of a Cannabinoid Receptor and Functional Expression of the Cloned cDNA. Nature. 346, 561-564. doi:10.1038/346561a0

Mechoulam, R., and Shvo, Y. (1963). Hashish. I. The Structure of Cannabidiol. Tetrahedron. 19, 2073-2078. doi:10.1016/0040-4020(63)85022-x

Moldrich, G., and Wenger, T. (2000). Localization of the CB1 Cannabinoid Receptor in the Rat Brain. An Immunohistochemical Study. Peptides. 21, 1735-1742. doi:10.1016/s0196-9781(00)00324-7 
Morimoto, S., Komatsu, K., Taura, F., and Shoyama, Y. (1998). Purification and Characterization of Cannabichromenic Acid Synthase from Cannabis Sativa. Phytochemistry. 49, 1525-1529. doi:10.1016/s0031-9422(98)00278-7

Morimoto, S., Tanaka, Y., Sasaki, K., Tanaka, H., Fukamizu, T., Shoyama, Y., et al. (2007). Identification and Characterization of Cannabinoids that Induce Cell Death through Mitochondrial Permeability Transition in Cannabis Leaf Cells. J. Biol. Chem. 282, 20739-20751. doi:10.1074/jbc.M700133200

Munro, S., Thomas, K. L., and Abu-Shaar, M. (1993). Molecular Characterization of a Peripheral Receptor for Cannabinoids. Nature. 365, 61-65. doi:10.1038/ 365061a0

Natarajan, S., Shunmugiah, K. P., and Kasi, P. (2013). Plants Traditionally Used in Age-Related Brain Disorders (Dementia): an Ethanopharmacological Survey. Pharm. Biol. 51, 492-523. doi:10.3109/13880209.2012.738423

National rInstitute of Public Health (2015). MHLW GRANTS SYSTEM [in Japanese]. Available at: https://mhlw-grants.niph.go.jp/node/55558 (Accessed April 26, 2021).

Pacifici, R., Marchei, E., Salvatore, F., Guandalini, L., Busardò, F. P., and Pichini, S. (2017). Evaluation of Long-Term Stability of Cannabinoids in Standardized Preparations of Cannabis Flowering Tops and Cannabis Oil by Ultra-highperformance Liquid Chromatography Tandem Mass Spectrometry. Clin. Chem. Lab. Med. 56, 94-96. doi:10.1515/cclm-2017-0758

Parsons, C. G., Danysz, W., and Quack, G. (1999). Memantine Is a Clinically Well Tolerated N-Methyl-D-Aspartate (NMDA) Receptor Antagonist-Aa Review of Preclinical Data. Neuropharmacology. 38 (6), 735-767. doi:10.1016/s00283908(99)00019-2

Putalun, W., Taura, F., Qing, W., Matsushita, H., Tanaka, H., and Shoyama, Y. (2003). Anti-solasodine Glycoside Single-Chain Fv Antibody Stimulates Biosynthesis of Solasodine Glycoside in Plants. Plant Cell Rep 22, 344-349. doi:10.1007/s00299-003-0689-3

Putalun, W., Tanaka, H., Wakana, A., Uto, T., and Shoyama, Y. (2015). Missiletype Molecular Breeding of Medicinal Plant Using Compact Monoclonal Antibody Gene. EC Agr. 2, 358-365.

Rafe De Crespigny (2007). A Biographical Dictionary of Later Han to the Three Kingdoms (23-220 AD). Leiden: Brill Academic Pub.

Romero, J., García, L., Cebeira, M., Zadrozny, D., Fernández-Ruiz, J. J., and Ramos, J. A. (1995). The Endogenous Cannabinoid Receptor Ligand, Anandamide, Inhibits the Motor Behavior: Role of Nigrostriatal Dopaminergic Neurons. Life Sci. 56, 2033-2040. doi:10.1016/0024-3205(95)00186-a

Sakamoto, S., Putalun, W., Pongkitwitoon, B., Juengwatanatrakul, T., Shoyama, Y., Tanaka, H., et al. (2012). Modulation of Plumbagin Production in Plumbago Zeylanica Using a Single-Chain Variable Fragment Antibody against Plumbagin. Plant Cell Rep. 31, 103-110. doi:10.1007/s00299-011-1143-6

Schuel, H., Goldstein, E., Mechoulam, R., Zimmerman, A. M., and Zimmerman, S. (1994). Anandamide (Arachidonylethanolamide), a Brain Cannabinoid Receptor Agonist, Reduces Sperm Fertilizing Capacity in Sea Urchins by Inhibiting the Acrosome Reaction. Proc. Natl. Acad. Sci. U S A. 91, 7678-7682. doi:10.1073/pnas.91.16.7678

Schwarz, H., Blanco, F. J., and Lotz, M. (1994). Anadamide, an Endogenous Cannabinoid Receptor Agonist Inhibits Lymphocyte Proliferation and Induces Apoptosis. J. Neuroimmunol. 55, 107-115. doi:10.1016/0165-5728(94)90152-x

Shan, S., Tanaka, H., and Shoyama, Y. (2001). Enzyme-linked Immunosorbent Assay for Glycyrrhizin Using Anti-glycyrrhizin Monoclonal Antibody and an Eastern Blotting Technique for Glucuronides of Glycyrrhetic Acid. Anal. Chem. 73, 5784-5790. doi:10.1021/ac0106997

Shoyama, Y., Takeuchi, A., Taura, F., Tamada, T., Adachi, M., Kuroki, R., et al. (2005). Crystallization of Deltal-tetrahydrocannabinolic Acid (THCA) Synthase from Cannabis Sativa. Acta Crystallogr. Sect F Struct. Biol. Cryst. Commun. 61, 799-801. doi:10.1107/S1744309105023365

Shoyama, Y., Tamada, T., Kurihara, K., Takeuchi, A., Taura, F., Arai, S., et al. (2012). Structure and Function of $\Delta 1$-tetrahydrocannabinolic Acid (THCA) Synthase, the Enzyme Controlling the Psychoactivity of Cannabis Sativa. J. Mol. Biol. 423, 96-105. doi:10.1016/j.jmb.2012.06.030

Shoyama, Y. (1993). "Biological Aspects on Marihuana, Cannabis Sativa L, and Biotechnological Investigation on Medicinal Plants," in Winged Been and Some Other Vegetables and Medicinal Plants in the Tropics and Subtropics. Editors W. Herath and S. Uemoto (Tokyo: Tokushu Nousanbutsu Kyokai), 141-200. Shoyama, Y., Hirano, H., Makino, H., Umekita, N., and Nishioka, I. (1977). Cannabis. X. The Isolation and Structures of Four New Propyl Cannabinoid
Acids, Tetrahydrocannabivarinic Acid, Cannabidivarinic Acid, Cannabichromevarinic Acid and Cannabigerovarinic Acid, from Thai Cannabis, 'Meao Variant'. Chem. Pharm. Bull. 25, 2306-2311. doi:10.1248/ cpb.25.2306

Shoyama, Y., Hirano, H., and Nishioka, I. (1994). Biosynthesis of Propyl Cannabinoid Acid and its Biosynthetic Relationship with Pentyl and Methyl Cannabinoid Acids. Phytochemistry. 23, 1909-1912. doi:10.1016/S00319422(00)84939-0

Shoyama, Y., Oku, R., Yamauchi, T., and Nishioka, I. (1972). Cannabis. VI. Cannabicyclolic Acid. Chem. Pharm. Bull. 20, 1927-1930. doi:10.1248/cpb. 20.1927

Shoyama, Y., Yamauchi, T., and Nishioka, I. (1970). Cannabis. V. Cannabigerolic Acid Monomethyl Ether and Cannabinolic Acid. Chem. Pharm. Bull. 18, 1327-1332. doi:10.1248/cpb.18.1327

Sirikantaramas, S., Morimoto, S., Shoyama, Y., Ishikawa, Y., Wada, Y., Shoyama, Y., et al. (2004). The Gene Controlling Marijuana Psychoactivity: Molecular Cloning and Heterologous Expression of Delta1-tetrahydrocannabinolic Acid Synthase from Cannabis Sativa L. J. Biol. Chem. 279, 39767-39774. doi:10.1074/ jbc.M403693200

Sirikantaramas, S., Taura, F., Tanaka, Y., Ishikawa, Y., Morimoto, S., Shoyama, Y., et al. (2005). Tetrahydrocannabinolic Acid Synthase, the Enzyme Controlling Marijuana Psychoactivity, Is Secreted into the Storage Cavity of the Glandular Trichomes. Plant Cell Physiol. 46, 1578-1582. doi:10.1093/pcp/pci166

Solymosi, K., and Köfalvi, A. (2017). Cannabis: A Treasure Trove or Pandora's Box? Mini Rev. Med. Chem. 17, 1223-1291. doi:10.2174/ 1389557516666161004162133

Stout, J. M., Boubakir, Z., Ambrose, S. J., Purves, R. W., and Page, J. E. (2012). The Hexanoyl-CoA Precursor for Cannabinoid Biosynthesis Is Formed by an AcylActivating Enzyme in Cannabis Sativa Trichomes. Plant J. 71 (3), 353-365. doi:10.1111/j.1365-313X.2012.04949.x

Sugiura, T., Kondo, S., Sukagawa, A., Nakane, S., Shinoda, A., Itoh, K., et al. (1995). 2-Arachidonoylglycerol: a Possible Endogenous Cannabinoid Receptor Ligand in Brain. Biochem. Biophys. Res. Commun. 215, 89-97. doi:10.1006/bbrc.1995. 2437

Taguchi, C., Taura, F., Tamada, T., Shoyama, Y., Shoyama, Y., Tanaka, H., et al. (2008). Crystallization and Preliminary X-ray Diffraction Studies of Polyketide Synthase-1 (PKS-1) from Cannabis Sativa. Acta Crystallogr. Sect F Struct. Biol. Cryst. Commun. 64, 217-220. doi:10.1107/S1744309108003795

Tanaka, H., and Shoyama, Y. (1999). Monoclonal Antibody against Tetrahydrocannabinolic Acid Distinguishes Cannabis Sativa Samples from Different Plant Species. Forensic Sci. Int. 106, 135-146. doi:10.1016/s03790738(99)00193-0

Taura, F., Morimoto, S., and Shoyama, Y. (1996). Purification and Characterization of Cannabidiolic-Acid Synthase from Cannabis Sativa L. J. Biol. Chem. 271, 17411-17416. doi:10.1074/jbc.271.29.17411

Taura, F., Dono, E., Sirikantaramas, S., Yoshimura, K., Shoyama, Y., and Morimoto, S. (2007a). Production of Delta(1)-tetrahydrocannabinolic Acid by the Biosynthetic Enzyme Secreted from Transgenic Pichia pastoris. Biochem. Biophys. Res. Commun. 361, 675-680. doi:10.1016/j.bbrc.2007.07.079

Taura, F., Sirikantaramas, S., Shoyama, Y., Shoyama, Y., and Morimoto, S. (2007b). Phytocannabinoids in Cannabis Sativa: Recent Studies on Biosynthetic Enzymes. Chem. Biodivers. 4, 1649-1663. doi:10.1002/cbdv.200790145

Taura, F., Sirikantaramas, S., Shoyama, Y., Yoshikai, K., Shoyama, Y., and Morimoto, S. (2007c). Cannabidiolic-acid Synthase, the ChemotypeDetermining Enzyme in the Fiber-type Cannabis Sativa. FEBS Lett. 581, 2929-2934. doi:10.1016/j.febslet.2007.05.043

Taura, F., Tanaka, S., Taguchi, C., Fukamizu, T., Tanaka, H., Shoyama, Y., et al. (2009). Characterization of Olivetol Synthase, a Polyketide Synthase Putatively Involved in Cannabinoid Biosynthetic Pathway. FEBS Lett. 583, 2061-2066. doi:10.1016/j.febslet.2009.05.024

Taura, F., Morimoto, S., Shoyama, Y., and Mechoulam, R. (1995). First Direct Evidence for the Mechanism of .DELTA.1-tetrahydrocannabinolic Acid Biosynthesis. J. Am. Chem. Soc. 117, 9766-9767. doi:10.1021/ja00143a024

Taura, F., Tanaya, R., and Sirikantaramas, S. (2019). Recent Advances in Cannabinoid Biochemistry and Biotechnology. ScienceAsia. 45 (5), 399-407. doi:10.2306/scienceasia1513-1874.2019.45.399

Terranova, J. P., Michaud, J. C., Le Fur, G., and Soubrié, P. (1995). Inhibition of Long-Term Potentiation in Rat Hippocampal Slices by Anandamide and 
WIN55212-2: Reversal by SR141716 A, a Selective Antagonist of CB1 Cannabinoid Receptors. Naunyn Schmiedebergs Arch. Pharmacol. 352, 576-579. doi:10.1007/BF00169393

Turner, C. E., Elsohly, M. A., and Boeren, E. G. (1980). Constituents of Cannabis Sativa L. XVII. A Review of the Natural Constituents. J. Nat. Prod. 43, 169-234. doi:10.1021/np50008a001

United Nations Office on Drugs and Crime (2017). World Drug Report 2017. (ISBN: 978-92-1-148291-1, eISBN: 978-92-1-060623-3. Vienna: United Nations publication. Sales No. E.17.XI.6).

Varga, K., Lake, K., Martin, B. R., and Kunos, G. (1995). Novel Antagonist Implicates the CB1 Cannabinoid Receptor in the Hypotensive Action of Anandamide. Eur. J. Pharmacol. 278, 279-283. doi:10.1016/0014-2999(95) 00181-j

Watanabe, K., Matsunaga, T., Kimura, T., Funahashi, T., Yamaori, S., Shoyama, Y., et al. (2005). Stereospecific and Regioselective Hydrolysis of Cannabinoid Esters by ES46.5K, an Esterase from Mouse Hepatic Microsomes, and its Differences from Carboxylesterases of Rabbit and Porcine Liver. Biol. Pharm. Bull. 28, 1743-1747. doi:10.1248/bpb.28.1743

Watanabe, K., Matsuda, M., Tateoka, Y., Kimura, T., Matsunaga, T., Tanaka, H., et al. (2000). Cross-Reactivity of Various Tetrahydrocannabinol Metabolites with a Monoclonal Antibody against Tetrahydrocannabinolic Acid. J. Health Sci. 46, 310-313. doi:10.1248/jhs.46.310

Watt, G., and Karl, T. (2017). In Vivo Evidence for Therapeutic Properties of Cannabidiol (CBD) for Alzheimer's Disease. Front. Pharmacol. 8, 20. doi:10. 3389/fphar.2017.00020

Weidenfeld, J., Feldman, S., and Mechoulam, R. (1994). Effect of the Brain Constituent Anandamide, a Cannabinoid Receptor Agonist, on the Hypothalamo-Pituitary-Adrenal axis in the Rat. Neuroendocrinology. 59, 110-112. doi:10.1159/000126646
Wenger, T., Tóth, B. E., and Martin, B. R. (1995). Effects of Anandamide (Endogen Cannabinoid) on Anterior Pituitary Hormone Secretion in Adult Ovariectomized Rats. Life Sci. 56, 2057-2063. doi:10.1016/0024-3205(95)00189-d

Wickens, A. P., and Pertwee, R. G. (1993). delta 9-Tetrahydrocannabinol and Anandamide Enhance the Ability of Muscimol to Induce Catalepsy in the Globus Pallidus of Rats. Eur. J. Pharmacol. 250, 205-208. doi:10.1016/00142999(93)90646-y

World drug report (2021). Booklet 3-Drug Market Trends: Opioids, Cannabis. Vienna: United Nations, Office on Drugs and Crime.

Conflict of Interest: YoS was employed by the company Bonac Corporation.

The remaining authors declare that the research was conducted in the absence of any commercial or financial relationships that could be construed as a potential conflict of interest.

Publisher's Note: All claims expressed in this article are solely those of the authors and do not necessarily represent those of their affiliated organizations, or those of the publisher, the editors and the reviewers. Any product that may be evaluated in this article, or claim that may be made by its manufacturer, is not guaranteed or endorsed by the publisher.

Copyright (c) 2022 Wenger, Watanabe, Sasaki, Kanazawa, Shimizu, Sirikantaramas, Shoyama, Taura, Morimoto and Shoyama. This is an open-access article distributed under the terms of the Creative Commons Attribution License (CC BY). The use, distribution or reproduction in other forums is permitted, provided the original author(s) and the copyright owner(s) are credited and that the original publication in this journal is cited, in accordance with accepted academic practice. No use, distribution or reproduction is permitted which does not comply with these terms. 